\title{
Thirty Years of Operating Experience with the Clauspol Process
}

\author{
C. Barrère-Tricca' ${ }^{1}$, J.P. Margotin ${ }^{2}$ and D.H. Smith ${ }^{1}$ \\ 1 Institut français du pétrole, 1 et 4, avenue de Bois-Préau, 92852 Rueil-Malmaison Cedex - France \\ 2 Procatalyse, 212, avenue Paul-Doumer, 92500 Rueil-Malmaison - France \\ e-mail: cecile.barrere-tricca@ifp.fr - jean-paul.margotin@procatalyse.com - dave.smith@ifp.fr
}

Résumé - Trente ans d'expérience industrielle du procédé Clauspol - Le procédé Clauspol, développé par l'IFP il y a une trentaine d'années, est un procédé de traitement de gaz de queue de Claus (TGT). Grâce à sa simplicité, à sa bonne opérabilité et à son faible coût, ce procédé a été licencié plus de 40 fois dans le monde entier, ce qui le place parmi les principaux TGT. Depuis le début, l'opérabilité et la technologie du procédé ont été continuellement améliorées, jusqu'à la dernière version, le Clauspol Booster 99.9+, qui permet, combiné au procédé Claus, d'atteindre des rendements de désulfuration supérieurs à 99,9\%. Pour arriver à de telles performances, les problèmes suivants ont été résolus :

- la corrosion apparue dans certaines des premières unités Clauspol est maintenant bien comprise et peut être évitée en suivant des règles simples de design, de construction et d'opération des unités ;

- la stabilité du catalyseur a été améliorée en diminuant la température du solvant, en remplaçant l'injection directe d'eau par un échangeur de chaleur, en changeant la formulation initiale du catalyseur et en améliorant le contrôle du rapport $\mathrm{H}_{2} \mathrm{~S}_{\mathrm{SO}_{2}}$ du gaz de queue de Claus ;

- la qualité du soufre produit est assurée par l'élimination de l'oxygène dans la charge du Clauspol en installant une couche de catalyseur spécifique dans le premier convertisseur Claus, en faisant particulièrement attention au design de la botte, par un contrôle régulier du niveau liquide dans le fond du réacteur et enfin en contrôlant le rapport $\mathrm{H}_{2} \mathrm{~S}_{\mathrm{SO}}$;

- avec l'expérience, la procédure de lavage à l'eau du réacteur tous les deux à quatre ans a été simplifiée. De plus, de nouveaux résultats de R\&D montrent que l'accumulation de solides dans le réacteur pourrait être évitée, éliminant les arrêts périodiques et réduisant la taille du réacteur.

Mots-clés : traitement de gaz, TGT, Clauspol, opération, corrosion, soufre, catalyseur, sels.

Abstract - Thirty Years of Operating Experience with the Clauspol Process - The Clauspol process, developed by IFP over thirty years ago, is a Claus Tail Gas Treatment (TGT) process. Because of its simplicity, ease of operation and low cost, the process has gained more than 40 industrial references worldwide, making it one of the most widespread TGT processes. From the beginning, the process operability and technology have been continuously improved to the point where the latest version, Clauspol Booster 99.9+, enables combined Claus-Clauspol sulfur recoveries exceeding $99.9 \%$ to be achieved. In arriving at the current performance levels, the following operational issues concerning industrial Clauspol plants were resolved:

- corrosion encountered in some of the first Clauspol plants is now well understood and is avoided by applying simple rules in the unit's design, construction and operation; 
- the catalyst stability has been improved by both lowering the temperature of the solvent, replacing direct injection of water by a heat exchanger, changing the initial catalyst formulation and improving control of $\mathrm{H}_{2} \mathrm{~S}_{\mathrm{SO}} \mathrm{O}_{2}$ ratio in the Claus tail gas;

- sulfur product quality is assured by eliminating oxygen in the Clauspol feed via installation of an oxygen-scavenging catalyst layer in the first Claus converter, with particular attention to the sulfur boot design, by a regular control of the liquid level in the bottom of the reactor and also by ensuring good control of $\mathrm{H}_{2} \mathrm{~S} / \mathrm{SO}_{2}$ ratio;

- with experience, the procedure of water-washing of the reactor every two to four years has become much simpler. Furthermore, new $R \& D$ results show that accumulations of solids in the reactor could be prevented, eliminating the need for periodic shutdowns and reducing the size of the reactor.

The above issues are discussed in this article.

Keywords: gas treatment, TGT, Clauspol, operation, corrosion, sulfur, catalyst, salts.

\section{PROCESS DESCRIPTION}

\subsection{The Process Concept}

The Clauspol process is based on the continuation, in a nonvolatile liquid organic solvent, of the Claus reaction (1) between the residual $\mathrm{H}_{2} \mathrm{~S}$ and $\mathrm{SO}_{2}$ present in Claus tail gases [1-3]:

$$
2 \mathrm{H}_{2} \mathrm{~S}+\mathrm{SO}_{2} \rightleftharpoons 3 / x \mathrm{~S}_{x}+2 \mathrm{H}_{2} \mathrm{O}
$$

The Claus tail gas enters the bottom of the reactor and flows up through a packed bed, countercurrently to the solvent (Fig. 1). $\mathrm{H}_{2} \mathrm{~S}$ and $\mathrm{SO}_{2}$ are absorbed by the solvent, which contains a proprietary catalyst. The reaction is performed at temperatures slightly above the sulfur melting point.

The produced sulfur is only slightly miscible with the solvent and, owing to its higher density, is recovered as a separate liquid phase from the bottom of the reactor. The process yields sulfur with an excellent purity, because of the extremely low solubility of both solvent and catalyst in the liquid sulfur.

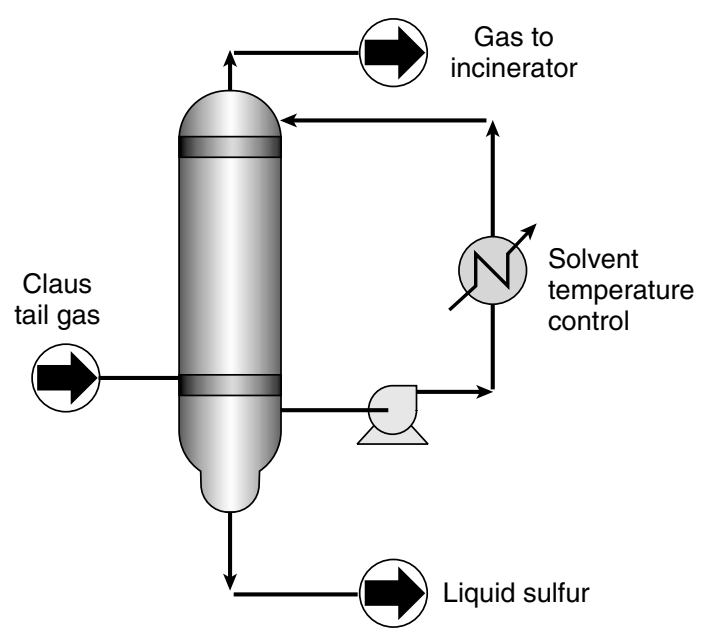

Figure 1

Basic Clauspol process.
Very high conversion rates are achieved if the $\mathrm{H}_{2} \mathrm{~S} \mathrm{SO}_{2}$ ratio is properly controlled and maintained near the stoichiometric value of two. Under such conditions the residual levels of $\mathrm{H}_{2} \mathrm{~S}+\mathrm{SO}_{2}$ in the Clauspol off-gas can be tailored down to $150 \mathrm{ppmv}$ (parts per million in volume expressed as elemental sulfur $\mathrm{S}_{1}$ ), depending on the size of the reactor. Levels as low as 100 ppmv of $\mathrm{H}_{2} \mathrm{~S}+\mathrm{SO}_{2}$ have been commonly obtained in industrial plants. The Clauspol process is flexible: it is one of the rare processes that are applicable in the range of $99.0 \%$ to 99.9\% sulfur recoveries. Catalyst and chemicals make-up are manufactured by Procatalyse.

The process reaction rate is limited primarily by the transfer of $\mathrm{H}_{2} \mathrm{~S}$ from the gas phase to the solvent. Therefore, the reactor is packed with high surface area ceramic intalox saddles.

The process is not very sensitive to feed inlet $\mathrm{H}_{2} \mathrm{~S}$ and $\mathrm{SO}_{2}$ concentrations, as long as the ratio $\mathrm{H}_{2} \mathrm{~S} / \mathrm{SO}_{2}$ remains constant. The Clauspol process has therefore a marked buffer capacity towards fluctuations of the Claus tail gas composition.

There are other sulfur components that are advantageously removed from Claus tail gas:

- elemental sulfur as vapor or as entrained liquid;

- $\mathrm{COS}$ and $\mathrm{CS}_{2}$.

Entrained liquid sulfur is fully removed by the reactor's packing, acting as a demister. The reactor temperature being lower than that of the Claus tail gas entering the reactor, sulfur vapor is partially condensed and recovered in the process.

$\mathrm{COS}$ and $\mathrm{CS}_{2}$ are only partially hydrolyzed to $\mathrm{H}_{2} \mathrm{~S}$ in the reactor through Reactions (2) and (3). Typical hydrolysis levels are respectively $40 \%$ and $15 \%$ of the $\mathrm{COS}$ and $\mathrm{CS}_{2}$ entering the reactor:

$$
\begin{aligned}
& \mathrm{CS}_{2}+\mathrm{H}_{2} \mathrm{O} \rightleftharpoons \mathrm{COS}+\mathrm{H}_{2} \mathrm{~S} \\
& \mathrm{COS}+\mathrm{H}_{2} \mathrm{O} \rightleftharpoons \mathrm{CO}_{2}+\mathrm{H}_{2} \mathrm{~S}
\end{aligned}
$$

The other compounds most frequently encountered in Claus tail gas have very little effect on the process. Water in the tail gas is a parameter taken into account for the design of the reactor; however, water contained in the Claus tail gas and produced by the reaction just flows through the reactor and is 
recovered as vapor in the off-gas. Carbon oxides, hydrogen, nitrogen and hydrocarbons have no effect. Unlike what is observed on solid catalysts in the Claus reactors, ammonia, if present, does not lead to plugging or catalyst deactivation in the Clauspol process, because of its solubility in the solvent. Furthermore, small quantities of ammonia appear to have a positive effect on the operation in normal operating conditions. Only residual oxygen might have some deleterious effect on the solvent but at the levels encountered in Claus tail gases (typically below 100 ppmv), such effects are too small to be observed. IFP's industrial experience with the process has shown that, under proper operation, the solvent remains stable and behaves satisfactorily for many years.

The packing induces very low pressure drop on the gas phase and avoids the need for any additional blower. The only rotating equipment needed by the process is the solvent circulation pump. Its flowrate needs to be kept at the minimum level necessary for complete wetting of the packing. Catalyst degradation compounds that accumulate on the packing, mainly sodium sulfate salts, need to be removed periodically by a water wash. Catalyst degradation being slow, the wash frequency is typically every two to four years.

The process needs no hydrogen, a decided cost and operating reliability advantage when compared to processes that convert the sulfur compounds to $\mathrm{H}_{2} \mathrm{~S}$ and recycle it back to the Claus unit. Clauspol, then, frees up existing Claus capacity by avoiding recycle streams to the Claus unit as well as not being dependent on hydrogen supply.

A final advantage of the process is its very low operating cost. In fact, the process only requires some power to drive the solvent circulation pump, a small amount of continuous catalyst make-up in order to maintain the catalytic activity in the reactor, and some cooling water for temperature control. Among these items, electrical power represents more than half of the total operating cost. Table 1 gives economic information for a Clauspol unit treating a typical Claus unit tail gas (combined production of 100 metric tons of sulfur per day).

Sulfur recoveries of $99.8 \%$ can be reached in the basic Clauspol process provided that the $\mathrm{COS}$ and $\mathrm{CS}_{2}$ have been hydrolyzed to below $300 \mathrm{ppmv}$ in the catalytic stages of the Claus plant.

\section{TABLE 1}

Economic information on a Clauspol unit treating a typical Claus unit tail gas (combined production of 100 metric tons of sulfur per day)

\begin{tabular}{l|c}
\hline Sulfur recovery (Claus + Clauspol) $(\%)$ & 99.8 \\
Investment* (ISBL 1999 Gulf Coast location) (millions US\$) & 4.5 \\
Catalyst consumption (millions US\$/y) & 0.024 \\
Initial solvent charge (millions US\$) & 0.13 \\
Power $(\mathrm{kWh} / \mathrm{h})$ & 100 \\
Cooling water $\left(\mathrm{m}^{3} / \mathrm{h}\right)$ & 30 \\
Low pressure steam (metric tons/h) & $1-3$ \\
\hline
\end{tabular}

\subsection{Setting the Limit Higher: Clauspol 99.9+}

99.9\% sulfur conversion in a Claus-plus-TGT plant implies a maximum of 300 ppmv residual sulfur components can be allowed to remain in the reactor effluent. With the Clauspol process, the $\mathrm{H}_{2} \mathrm{~S}$-plus- $\mathrm{SO}_{2}$ level in the off-gas can easily be in the range 100-150 ppmv. Going to lower levels is possible but probably not economical because of the fairly large reactor volume that would be required. Thus, the only way to reach this $300 \mathrm{ppmv}$ level is to remove, as much as possible, the other sulfur compounds, i.e., $\mathrm{COS}, \mathrm{CS}_{2}$, and elemental sulfur (Fig. 2).

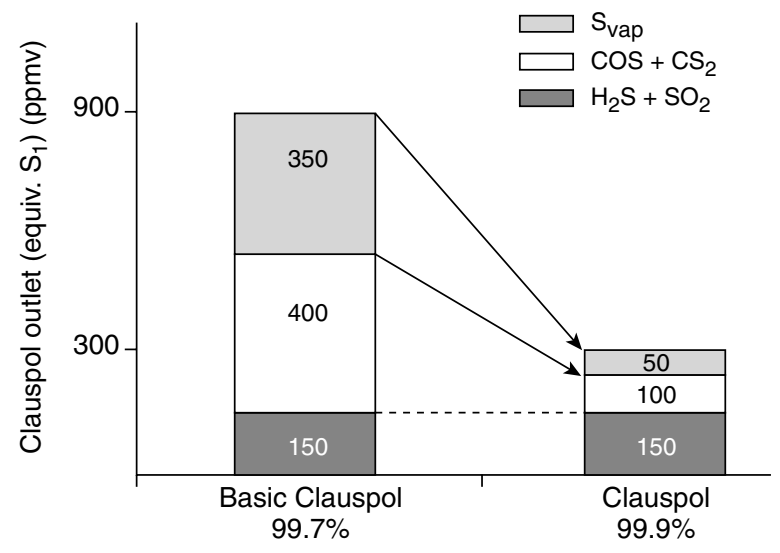

Figure 2

Sulfur distribution in the basic Clauspol off-gas for overall $99.9 \%$ sulfur recovery.

\subsection{1 $\mathrm{COS}$ and $\mathrm{CS}_{2}$ Removal}

The extents of the $\mathrm{COS}$ and $\mathrm{CS}_{2}$ hydrolysis reactions are limited to $40 \%$ and $15 \%$ respectively, in the reactor. The residual amounts of these compounds can be reduced to the desired level (typically below 100 ppmv for COS-plus-CS 2 ) if the hydrolysis is carried out in the catalytic stages of the Claus unit. This is made possible by choosing a Claus catalyst with appropriate hydrolytic activity.

$\mathrm{COS}$ and $\mathrm{CS}_{2}$ are formed in the Claus furnace because $\mathrm{CO}_{2}$ and hydrocarbons are present in the acid gas feed. The resulting concentrations depend on several parameters such as flame temperature, flowrate, and hydrocarbons present in the sweetening unit effluent, but in most cases $\mathrm{COS}$ and $\mathrm{CS}_{2}$ levels range between $0.2 \%$ and $0.5 \%$ at the inlet to the first Claus catalytic converter. These concentrations must be reduced in the Claus effluent by over $95 \%$ to the desired 100 ppmv, so that the 300 ppmv overall sulfur specification at the reactor outlet will be met (Fig. 2). Only the most active specialized $\mathrm{TiO}_{2}$ Claus catalysts (Procatalyse CRS 31) can fulfill this requirement [4]. The promoted alumina catalysts, whatever their origin, are not active enough to achieve a 
sufficiently high $\mathrm{COS}$ and $\mathrm{CS}_{2}$ conversion at relatively low temperatures, ranging from $300^{\circ}$ to $350^{\circ} \mathrm{C}$, that are necessary for maximum thermodynamic conversion.

\subsubsection{Elemental Sulfur Removal: The Solvent "Desaturation Loop"}

Elemental sulfur in reactor effluent is present only as vapor in equilibrium with liquid sulfur formed in the reactor. This corresponds to around $350 \mathrm{ppmv}$. Cooling the off-gas before incineration is one way to reduce this amount, but cooling below the sulfur melting point will result in solid sulfur deposition. Operating the reactor at a lower temperature would also result in a smaller amount of elemental sulfur vapor in the off-gas, with no additional equipment. However, sulfur formed in the solvent by the reaction would then settle as a solid on the packing, which would rapidly plug the reactor.

There is another route to reduce the amount of sulfur in the off-gas. Since the solubility of elemental sulfur in the solvent is low, this enables the removal of the sulfur, formed by the reaction, as a separate liquid phase. Under the normal operating conditions of the basic Clauspol, the solvent in equilibrium with liquid sulfur contains around $2 \mathrm{wt} \%$ of

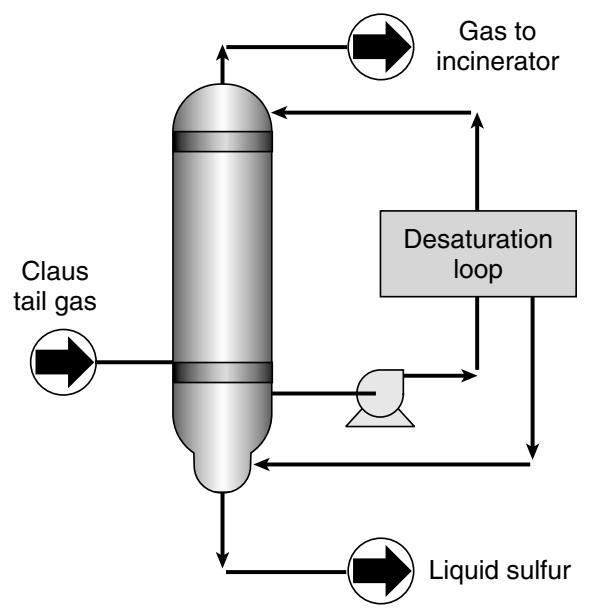

Figure 3

Clauspol with Desaturation loop (Clauspol booster 99.9+). elemental sulfur. Contacting the off-gas with an unsaturated solvent (containing less sulfur than at equilibrium with liquid sulfur) results in a much lower elemental sulfur concentration in the vapor. The proprietary solvent Desaturation loop, developed by IFP [5, 6], enables the reactor to be operated using such an unsaturated solvent, without modifying the basic reactor features. It is thus possible to reduce the amount of sulfur vapor in the reactor effluent to levels as low as 50 ppmv (Fig. 2) or if required lower; only marginal additional cost is required. The Clauspol process with the Desaturation loop is illustrated in Figure 3.

\subsubsection{Desaturation Loop Operation}

A fraction of the solvent from the recirculation loop is withdrawn and cooled in a heat exchanger, to temperatures where solid sulfur precipitates (typically $50-70^{\circ} \mathrm{C}$ ). Solid sulfur is then separated from the cold solvent with a filter.

The clarified solvent from the filter is sent back to the solvent circulation loop.

The slurry resulting from the discharge of the filter is heated in a heat exchanger and sent to the bottom of the reactor where the liquid sulfur settles.

This loop maintains unsaturated solvent throughout the packed bed, even though saturated solvent is present at the bottom of the reactor.

The equipment needed for the Desaturation loop is comparatively small, resulting in a minor additional investment cost for installation. This additional investment increases the cost of the TGT unit by approximately $10 \%$.

For the same reason, operating costs of the Desaturation loop (mainly cooling water and low pressure steam) are also comparatively low, increasing those of the entire unit by around $20 \%$.

\section{INDUSTRIAL REFERENCES}

The Clauspol process has now been licensed throughout the world more than 40 times since 1971, making it one of the most widespread TGT processes. These units' capacities range from 30 to $800 \mathrm{t} / \mathrm{d}$ in combined Claus plus Clauspol. The last Clauspol industrial references are given in Table 2.

TABLE 2

Latest Clauspol industrial references

\begin{tabular}{l|c|c|c|c}
\hline Customer & Location & Capacity of the upstream Claus unit (t/d) & Start-up date & Overall yield (\%) \\
\hline Chevron Chemical SA & Gonfreville (France) & 25 & 1993 & 99.0 \\
Total & Normandy Refinery (France) & 110 & 1993 & 99.8 \\
Total & Normandy Refinery (France) & 125 & 1993 & 99.8 \\
WEPEC & Dalian (PRC) & 350 & 1995 & 99.5 \\
Corpoven & Puerto La Cruz (Venezuela) & 150 & 2001 & 99.7 \\
KNPC & Shuaiba Refinery (Kuwait) & 700 & Awarded & 99.5 \\
\hline
\end{tabular}




\section{MAIN OPERATIONAL ISSUES}

The main operating problems that were observed in the industrial Clauspol units are reviewed in this section and the solutions that were implemented are discussed in the following pages.

\subsection{Corrosion}

\subsubsection{Corrosion in the Gas Sections}

Gas phase corrosion in a Clauspol unit is qualitatively analogous to that of a Claus unit with the only difference being that the gas temperature is lower in the Clauspol unit$120^{\circ} \mathrm{C}$ versus the Claus unit's minimum of $130-140^{\circ} \mathrm{C}$ at the outlet of the final condenser. As long as gas is the only phase present, the corrosion rate is very small: between 0.1 and $0.2 \mathrm{~mm}$ per year. A 3 to $5 \mathrm{~mm}$ corrosion allowance in the design is generally used to guarantee the installation for twenty years. Higher values are used by IFP in the case where there are doubts concerning insulation and installation efficiencies, or if the outside temperatures can be relatively low, e.g., $-25^{\circ} \mathrm{C}$.

However, corrosion can occur in the gas sections if an aqueous liquid phase is allowed to form.

The gas effluents from both Claus and Clauspol units contain between $30 \%$ and $36 \%$ water vapor. Inside the reactor and piping, vessel metal wall temperatures are lower than the bulk fluid temperature causing a layer of sulfur solids to deposit on the inside walls. Should the metal skin temperature be lower than that of the dew point of the gas/water vapor mixture, i.e., $69-74^{\circ} \mathrm{C}$ depending on water concentration, water will condense as it diffuses through the sulfur film and reaches the cooler metal surface. A corrosive environment is established that comprises a liquid/solid/vapor system of water, $\mathrm{SO}_{2}$ and sulfur. The possibility of capillary condensation of water in the sulfur layer exists. If it occurs, the situation will be aggravated because capillary condensation increases the dew point by a few degrees.

\section{Faulty Thermal Insulation}

In practice and theory alike, maintaining metal wall temperature above the water dew point suffices to minimize corrosion. A proper thickness of insulation is all that is required. Several Clauspol units, mostly the first installations, were subject to corrosive attack caused by faulty or deteriorating insulation.

Faulty thermal insulation is rarely due to an insufficient thickness specification but rather to various problems arising during detailed design and construction, improper installation of insulation or its deterioration with time. For example, the corrosion that developed rapidly at manhole covers resulted from water condensing and flowing down the interior walls of the reactor. Deteriorating insulation can also cause rainwater to enter, often at the top of the reactor, causing cold spots and subsequent water condensation on the inside wall.

Clauspol units installed in the last ten to fifteen years are designed with $80-120 \mathrm{~mm}$ insulation thickness. These units have not exhibited signs of corrosion although one unit had corrosion signs due to poorly installed insulation. One unit, for which the insulation thickness was $60 \mathrm{~mm}$, was even operated for sixteen years before generalized corrosion was observed after a water wash. The insulation itself exhibited generalized deterioration from aging.

\section{Existence of Thermal Conductivity "Bridges"}

Thermal conductivity "bridges" can be established by installation of external metallic structure supports that produce steel contacts (an exposed I-beam, for example) which significantly increase the rate of heat transfer from the vessel wall to the exterior. One could thereby see the structure corrosion print on the reactor inner wall after operation. It is necessary sometimes to protect the affected area with a stainless shroud. Heat transfer calculations can provide two solutions to avoid this problem:

- the best solution is to install thermal insulating material between the I-beam and the vessel wall;

- it is also possible to reduce heat transfer rates by insulating the I-beam that supports the metal structure. Although less efficient, this solution, combined with an increase in insulation thickness, is easier to achieve in an existing unit than inserting the insulating layer directly to the vessel wall between the I-beam and the vessel wall.

\section{Unintentional Presence of a Liquid Water Phase at any Point in the Process}

In first generation units, liquid water was injected directly into the Clauspol inlet gas to control the reactor temperature. Theoretically, the injected condensate is immediately vaporized due to the existing operating conditions. In some units, owing to partial plugging of the injection device, some liquid water drained on the reactor wall under the inlet gas line, thus creating the high corrosive medium discussed above. In those cases, the reactor wall was pierced within a few months after start-up. After that, all condensate injections were relocated in the polyethylene glycol (PEG) circulation line. However, the problem has been completely eliminated in today's units using an exchanger to control the reactor temperature. This will be described later. Purging the vessels and piping with a small amount of PEG under nitrogen after shutdowns (e.g., after water washing) will avoid water accumulation in low points and has proved successful.

\subsubsection{Liquid Phase Corrosion}

Measured liquid phase corrosion rates are close to those of the vapor phase. Under normal operation, rapid liquid phase corrosion is not to be encountered. However, rapid corrosion 
of the solvent storage tank has once been observed during the washing of the reactor. In fact, liquid water (30\%) was inadvertently present in the solvent storage tank, which resulted in its being pierced in less than two weeks (time necessary for the washing operation), because of the presence of both water and sulfur.

Corrosion aging tests have been performed recently at $60^{\circ} \mathrm{C}$ on two diphasic systems: PEG and sulfur and PEG containing $30 \%$ water and sulfur, both on carbon steel samples and on resin-coated carbon steel samples. By the end of one month, the carbon steel sample in the first system exhibited very little corrosion while the sample in the second system was considerably corroded. Regardless of the environment, the resin-coated samples were not damaged at all. Due to the low residence time of the solvent in the storage tank, it is therefore advisable to coat the solvent storage tank internal walls with impermeable resin. Nevertheless, it is obviously highly inadvisable to introduce water in the solvent storage tank.

\subsubsection{Presence of Chlorine Compounds}

Clauspol reactor internals were originally specified to be fabricated from 304L stainless steel. Incidents, which occurred recently, have shown strong evidence of chlorides present in the reactor environment with both gas- and liquidphase corrosion appearing in the stainless steel equipment. The chloride source was found to be the catalyst make-up. As a first step, IFP replaced the internals with $316 \mathrm{~L}$ stainless steel. Now that the Procatalyse Company has taken complete charge of all catalyst manufacturing operations, this problem is unlikely to reappear.

\subsection{Catalyst Stability}

\subsubsection{Solvent Temperature}

Since the first industrial application, the reactor temperature has been lowered from $135^{\circ}$ to $120-122^{\circ} \mathrm{C}$. This slows the catalyst deterioration rate by a factor of three and diminishes elemental sulfur vapor in the Clauspol effluent by a factor of two.

\subsubsection{Solvent Temperature Control Loop}

The Claus reaction is exothermic, and the incoming Claus unit tail gas is usually at temperatures between $125^{\circ}$ and $144^{\circ} \mathrm{C}$, sometimes even higher. As the circulating stream must be maintained in the $120-122^{\circ} \mathrm{C}$ range, heat must be rejected. In the past the heat was removed by direct water injection in the gas and later on in the solvent. This water was evaporated and recovered with the Clauspol off-gas. The addition of a heat exchanger to cool the solvent loop permits better control of the solvent temperature and, by avoiding the injection of free water, helps to maintain a higher catalytic activity as well as a longer catalyst service life. Furthermore, avoiding injection of free water into the reactor also helps to maintain the thermodynamic equilibrium of the Claus reaction at the highest possible sulfur conversion.

Today, the solvent cooler exchanger is sized to remove heat from the system by indirect exchange with a tempered water cooling system. The exchanger is vertical with the solvent traveling up the tube side and tempered water in the single-pass shell side. The exchanger is piped to a cooler for tempered water that can either be a water-cooled (often a plate exchanger) or an air-cooled exchanger.

To avoid fouling due to sulfur freezing in the exchanger and all the ensuing effects (such as reduced heat transfer by conduction, reduced overall heat exchange coefficient, reduced heat transfer, increased pressure drop), the operating conditions take into account a small difference in temperature between water and PEG as shown below:

$\begin{array}{ll}\text { - PEG inlet temperature: } & 120.4^{\circ} \mathrm{C} \\ \text { - water inlet temperature: } & 100^{\circ} \mathrm{C} \\ \text { - PEG outlet temperature: } & 120^{\circ} \mathrm{C} \\ \text { - water outlet temperature: } & 107^{\circ} \mathrm{C} .\end{array}$

\subsubsection{Catalyst Formulation}

Three similar catalyst formulas having nearly the same catalyst activity have been used industrially. In order of their introduction, formulations were the following:

- potassium salt of organic acid A;

- mixture of potassium and sodium salts of organic acid A (at $10 \mathrm{~mol} \%$ potassium);

- sodium salt of organic acid B.

One reason for this change was due to cost considerations; from the first catalyst formula to the third, the catalyst cost has been reduced by a factor of five. Another very important reason for the change is the better stability of the new catalyst formula especially to low ratio operation that resulted in a much lower rate in catalyst degradation and the ensuing salt formation.

Recently, the formulation has been slightly modified. Now, catalyst is supplied directly by the Procatalyse Company.

\subsubsection{Improved $\mathrm{H}_{2} \mathrm{~S} / \mathrm{SO}_{2}$ Ratio Control with Reliable, Accurate On-Line Analyzers}

The $\mathrm{H}_{2} \mathrm{~S} / \mathrm{SO}_{2}$ ratio is a key parameter for the design and performance of the Clauspol process. If high $\mathrm{H}_{2} \mathrm{~S} / \mathrm{SO}_{2}$ conversion levels are to be reached in the Claus reaction whether it be in the Claus unit or in the Clauspol unit, this ratio should be kept as close as possible to the stoichiometric value of two. Also, good control of this ratio limits catalyst degradation: an excess of $\mathrm{SO}_{2}$ rapidly increases the rate of undesirable side reactions. In Clauspol units, this can be compensated to some extent by increasing catalyst make-up. However, if this excess is too large or lasts too long, inevitably some destruction of the catalytic complex occurs. 
Also running the unit for long period of time under these conditions will lead to difficulties regarding sulfur settling and deterioration in sulfur color. A continuous operation with excess of $\mathrm{SO}_{2}$ can also increase the corrosion rate.

Improved ratio control of the Claus tail gas was made possible due to the development of reliable and accurate short response time on-line photometric analyzers that are installed on the outlet of the Claus unit and control the air inlet of the Claus burner [7,8].

\subsection{Sulfur Product Quality}

The sulfur produced by the Clauspol process is, under normal operating conditions, $99.9 \%$ pure and bright yellow with an ash content below $100 \mathrm{ppm}$ and less than $300 \mathrm{ppm}$ of carbonaceous material. Following a few guidelines will ensure producing good quality sulfur.

\subsubsection{Avoid the Presence of Oxygen in Both Claus and Clauspol Units}

In addition to accelerating catalyst loss and formation of sodium sulfate, oxygen will oxidize PEG resulting in difficulties in decanting the sulfur in the bottom of the reactor and increasing the sulfur content in the solvent and PEG concentration in the sulfur product. At start-up, oxygen should be removed by means of a series of nitrogen purges in the reactor and PEG circulating loop. Under normal operations, Claus units operate under a reducing environment, but the presence of a few hundred ppm of oxygen is nevertheless possible due to poor mixing of $\mathrm{H}_{2} \mathrm{~S}$ and air in the combustion chamber or as a result of faulty burner in the reheaters upstream of the catalyst beds, if this reheating method is used. Outside of improving burner performance, the problem is eliminated by using Procatalyse's AM catalyst or equivalent in the Claus unit catalytic beds, which assures the elimination of oxygen at the same time maintaining the Claus conversion efficiency.

\subsubsection{Good Control of Sulfur Product Withdrawal}

Sulfur withdrawal at the bottom of the reactor is controlled by an equilibrating leg that is tied to the sulfur storage pit via a hydraulic guard system. The role of the equilibrating leg is to adjust the sulfur level in the reactor boot. This level corresponds to a sulfur residence time, which conditions the extent of separation between the solvent phase and the liquid sulfur phase. The correct decanting separation requires the following conditions:

- a difference in density between the two phases;

- a sufficient residence time in the boot.

It is therefore recommended to adjust the sulfur level in the boot by adjusting, once a month, the solvent level in the bottom of the reactor. The solvent level depends on PEG losses in the gas, in the sulfur, on the packing and by sampling.

\subsubsection{Skimming the Interface}

Catalyst deterioration causes the formation of sodium sulfate salt crystals $\left(\mathrm{Na}_{2} \mathrm{SO}_{4}\right)$ in the PEG that accumulate generally in the bottom of the reactor at the interface between the solvent and liquid sulfur. This causes separation problems between solvent and liquid sulfur. To eliminate the salt accumulation at the interface, the interface is skimmed regularly, one or two hours per week, and sent to the top of the reactor. The salt deposits on the packing and the interface are improved. In current Clauspol units, the reactor packing serves as a trap for the salts as well as providing gas-liquid surface area.

\subsection{Water-Washing the Reactor}

\subsubsection{Present Procedure}

After about two years of service, the quantity of crystals deposited on the packing may cause the reactor pressure drop to reach the maximum acceptable of 70 mbar. The unit is then taken out of service and the packing is washed with water.

Once the unit is shut down, the column is washed by solvent circulation at $125^{\circ} \mathrm{C}$ in order to eliminate the sulfur deposited on the packing. The solvent is then cooled down to $80^{\circ} \mathrm{C}$ and the sulfur which precipitates is extracted. The cooled solvent is then used to cool the packing and is transferred to the storage tank. The sodium sulfate deposited on the packing remains wet with PEG. Industrial experience has shown the weighted ratio of PEG to salt is in the neighborhood of 1.33 after $24 \mathrm{~h}$ of draining out. The elimination of PEG and sodium sulfate using $40^{\circ} \mathrm{C}$ circulating water takes two to three hours. The result is a twophase system, an organic phase and an aqueous phase. The quantity of sulfate deposited on the packing before the water wash can be estimated given the total quantity of catalyst added to the process. The organic phase is recovered for reuse in the process during the next start-up. The heavier aqueous phase is decanted from the lower part of the reactor and diluted with water to lower the crystallization temperature. Composed of $99 \%$ water and salts, this stream can be sent to the refinery water treatment system as long as its PEG content is less than $100 \mathrm{ppm}$ - generally the case after mixing with used water of the refinery. IFP has demonstrated that concentrations under $40 \mathrm{~g} / \mathrm{l}$ PEG do not affect the performance of ordinary waste treatment plant bacteria. Once the organic phase has been recovered, the packing is carefully rinsed with fresh water as long as the remaining water contains more than $1 \%$ salt. Normally, three or four one-hour rinses suffice. Allowing the packing to drain between rinses improves the effectiveness of the operation. Sulfur is virtually insoluble in water but any sulfur remaining on the packing after rinsing is dissolved during start-up. 


\subsubsection{Tomorrow's Units}

Washing operations have been mastered but remain relatively long at about two weeks and are somewhat delicate procedures. If the procedures are not carried out correctly, line corrosion and plugging problems can occur, for instance if some wash water is not carefully eliminated from all parts of the unit before start-up. To reduce the shutdown frequency, it is necessary to avoid salt formation and deposition, and IFP is developing a system that allows the salts to be extracted as soon as they are created (Fig. 4).

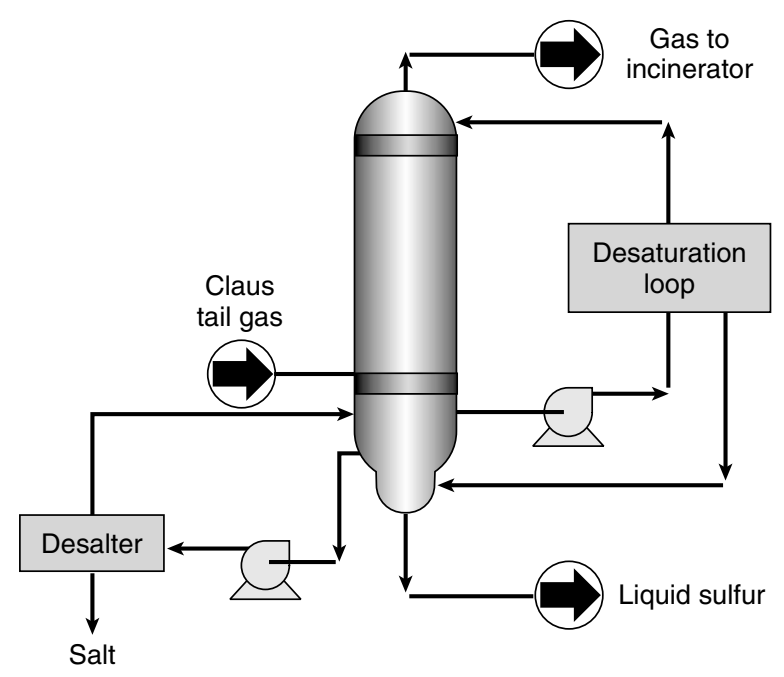

Figure 4

Block flow diagram of the Clauspol booster 99.9+ process with the salt elimination package.

The principle is to withdraw the salt-rich solvent-sulfur interface in small amounts, treating the slipstream in a small package that operates independently of the Clauspol unit. The two effluent streams from this package are the solvent, essentially free of salts which is returned to the reactor, and the salt solution which can be sent to the water treatment plant.

The main advantages of the salt elimination system are as follows:

- no shutdown of Clauspol unit excepted every five years for the turnaround schedule of Claus unit;
- reduced reactor size: the role of the reactor packing is now simply that of assuring the reaction without needing to act as a sulfate storage medium for avoiding sulfur-PEG decanting problems.

The cost of the system is marginal and largely compensated by the savings due to reduced reactor size.

\section{CONCLUSION}

The Clauspol process has undergone continuous operational and technological improvements as a result of thirty years of industrial experience and continuous development. Problems of corrosion, catalyst stability and sulfur quality have been eliminated. As a result, the process is simpler, smoother running and more cost-effective. Encouraging developments like the salt eliminator package ensure that this benchmark process continues to be even more competitive.

\section{REFERENCES}

1 Barthel, Y., Bistri, Y., Deschamps, A., Renault, P. and Simandoux, J.C. (1971) IFP Process Reduces Sulfur in Claus Unit Tail Gas. Canadian Petroleum, October, 48-51.

2 Barthel, Y., Bonnifay, P., Franckowiak, S., Renault, P., Deschamps, A. and Andrews, J.V. (1974) IFP Process for Claus Unit Tail Gas Cleanup Features Design Simplicity and Low Cost. Canadian Petroleum, November, 23-25.

3 Barthel, Y. and Gruhier, H. (1979) The IFP Clauspol 1500 Process, Eight Years of Industrial Experience. Proc. of 4th International Symposium, Antwerp, Belgium, October 17-19, Chem. Eng. Monogr. (Large Chem. Plants), 10, 69-86.

4 Benayoun, B., Dezael, C., Lecomte, F. and Ray, J.L. (1996) Improve your Claus Sulfur Recovery with a Titanium Dioxide Catalyst and the New Clauspol 99.9 Tail Gas Treatment. Sulfur, Vancouver, Canada, October 20-23.

5 Streicher, C. (1997) Clauspol Achieves 99.9\% Sulfur Recovery. Sulfur, 250, 60-64.

6 Lecomte, F., Streicher, C., Smith, D. and Benayoun, D. (1998) Minimizing TGTU $\mathrm{SO}_{2}$ Emissions with New Technology. GPA European Chapter, Zurich, Switzerland, September 2325.

7 Bourbonneux, G. (1993) Amélioration des performances des unités de récupération de soufre en raffinerie. Pétrole et Techniques, 383, 25-39.

8 Hennico, A., Barthel, Y., Benayoun, D. and Dezael, C. (1994) Clauspol 300: the New IFP TGT Process. AIChE Summer National Meeting, Denver, Colorado, USA, August 14-17.

Final manuscript received in January 2001 